\title{
English Springer Spaniel
}

National Cancer Institute

\section{Source}

National Cancer Institute. English Springer Spaniel. NCI Thesaurus. Code C53888.

The Eng lish Springer Spaniel is a compact, medium-sized dog with long pendant ears.

The medium-length coat is flat or wavy and feathered, and comes in liver and white, and black and white, blue or liver roan. Height: 18-21 inches (46-56 cm.) Weight: 40-55

pounds (18-25 kg.) 